\title{
Festschrift for Leonard Bickman: Introduction to The Future of Children's Mental Health Services Special Issue
}

\author{
Sonja K. Schoenwald ${ }^{1}$ (1) $\cdot$ Catherine P. Bradshaw ${ }^{2} \cdot$ Kimberly Eaton Hoagwood $^{3} \cdot$ Marc S. Atkins $^{4} \cdot$ Nicholas lalongo $^{5}$. \\ Susan R. Douglas ${ }^{6}$
}

Published online: 26 July 2020

(c) Springer Science+Business Media, LLC, part of Springer Nature 2020

\begin{abstract}
This introductory article describes the genesis of the Festschrift for Leonard Bickman and of this Festschrift special issue entitled, The Future of Children's Mental Health Services. The special issue includes a collection of 11 original children's mental health services research articles, broadly organized in accordance with three themes (i.e., Improving Precision and Use of Service Data to Guide Policy and Practice, Implementation and Dissemination, and Preparing for Innovation), followed by an interview-style article with Bickman. Then follows a featured manuscript by Bickman himself, three invited commentaries, and a compilation of letters and notes in which colleagues reflect on his career and on their experiences of him. The introduction concludes with a few thoughts about the future of children's mental health services portended by the extraordinary scholarly contributions of Bickman and those who have been inspired by him.
\end{abstract}

Keywords Leonard Bickman Festschrift · Children's mental health services · Implementation and dissemination · Artificial intelligence $\cdot$ Precision mental health

In May 2018, a group of about 40 researchers, colleagues, friends, and family members gathered in person and remotely for a Festschrift at the Johns Hopkins Bloomberg School of Public Health to honor the work of Leonard Bickman and his contributions to advance children's mental health. The word Festschrift is German, and roughly translates into a festival or celebration of the work of an author. With this goal in mind, it was through innovative research presentations, along with some stories and a few songs,

This article is part of the Festschrift for Leonard Bickman Special Issue on The Future of Children's Mental Health Services.

Sonja K. Schoenwald

sonja.schoenwald@oslc.org

1 Oregon Social Learning Center, 10 Shelton McMurphy Blvd., Eugene, OR 97401, USA

2 University of Virginia, Charlottesville, USA

3 New York University Grossman School of Medicine, New York, USA

4 University of Illinois Chicago, Chicago, USA

5 Johns Hopkins Bloomberg School of Public Health, Baltimore, USA

6 Vanderbilt University, Nashville, USA those gathered recognized "Len", as his colleagues refer to him, for his scholarship and deep devotion to the welfare of children and families through his seminal research, and his mentoring to a cadre of graduate students and colleagues.

The idea for the Festschrift had its earliest origins in the wise counsel that Len provided Nick Ialongo and his colleagues as a member of the Scientific Advisory Committee for their Advanced Center for Services and Intervention Research. For nearly a decade, Nick and his center colleagues looked forward to Len's annual visits to Baltimore, not only in anticipation of his invaluable insights and advice, but also because they wanted to hear more about the innovative child mental health services research that he and his Vanderbilt colleagues were doing. But the idea of a Festschrift in honor of Len's enormous contributions to child mental health services research, did not come together fully until a 2017 conversation Nick had with Len and Michael Lindsey, Director of New York University's McSilver Institute for Poverty Policy and Research. Len was once again being generous with his time and was providing Michael and Nick invaluable advice during the call. By the end of the call both Nick and Michael felt it was time to publicly honor Len as not only a great researcher, but as a wonderful mentor and generous colleague. With Len's input and guidance 
from colleagues in the field of child mental health services research, a committee consisting of the authors of this paper (i.e., Nick Ialongo, Kimberly Hoagwood, Marc Atkins, Sonja Schoenwald, Catherine Bradshaw, Susan Douglas) organized the Festschrift. It began with Len's students, mentees, and collaborators sharing how they came to know and/or work with Len and their impressions of the impact of Len's work on their careers and/or on the field of mental health services research. As is typical for a Festschrift, the event included a series of presentations by emerging leaders in child mental health services research, who presented on the innovative work they were engaged in which was inspired by Len's research. Members of his family, including children and grandchildren also shared their perspectives of his role as a researcher and a family member. Finally, the Festschrift concluded with a large group discussion of the future of child mental health services research, with Len sharing his wisdom and insights as always.

In keeping with the traditional format of a Festschrift, we have followed up with a publication celebrating and recognizing Len's research, and derivations of that work by other scholars who were inspired or informed by his work. Toward that end, we organized this special issue entitled The Future of Children's Mental Health Services in Len's honor. We selected Administration and Policy in Mental Health and Mental Health Services Research as the Festschrift outlet not only because Len founded the journal, but because it is a seminal journal that has had a significant role in advancing the field of mental health services research. In addition to the open call for original peer-reviewed papers, we invited a few select papers, including commentaries and a paper by Len himself. The special issue concludes on a more personal note, with brief letters and notes by colleagues and collaborators of Len's, in which they reflect on the impact Len has had on their own work and the field.

Together, this collection of papers featured in the Festschrift is intended to reflect on and address some of the most pressing questions for today's mental health services for children. In the remaining sections of this introduction to the special issue, we describe specific elements and themes of the collection of articles, and offer some concluding thoughts about the future of children's mental health services in light of the work by Len, and others inspired by it.

\section{Content and Organization of the Special Issue}

Shortly after the Hopkins event was held, we released an open call for original papers to appear in this special issue of Administration and Policy in Mental Health and Mental Health Services Research. Specifically, we called for papers that address the most pressing questions for today's mental health services for children. We were interested in soliciting (1) Original empirical research that examines delivery, effectiveness, or quality of mental health services for children and families; (2) Reviews and perspectives that integrate key conceptual issues and advance theoretical knowledge; and (3) Papers focused on policy, program development, and implementation science related to child mental health services. Consistent with Len's discipline-spanning research, the call especially encouraged submissions that include coauthorship across traditional disciplines of mental health services research. We were pleased by the number of letters of interest we received and by the submissions we subsequently invited. All submissions underwent the standard doubleblinded review process, the outcome of which yielded the set of 11 original papers in this issue. The articles reflect advances in three arenas Len pioneered or for which his intellectual leadership and research laid some of the groundwork for advancement. They are broadly organized into the following three themes.

\section{Theme One: Improving Precision and Use of Service Data to Guide Policy and Practice}

Since its founding in 1999, this journal has had an explicit focus on leveraging methods to improve knowledge about service access, quality and efficiency (Bickman 1999). Accurate identification of service needs continues to be critical for program and policy developers in their goals to increase access and judiciously allocate effective and equitable services. Toward that end, the articles featured in this section of the special issue describe three approaches to such identification and the results of their use. The authors of the first two studies leveraged administrative data from government agencies to identify and characterize, in the first instance (Dickson et al. 2020) high-cost users of youth outpatient mental health care, and, in the second instance (Duncan et al. 2020), regional variation in children's unmet need and predictors of that. These studies exemplify uses of administrative data to identify nuances in population, system, and service level data that can be harnessed to sharpen the focus of policy and practice on strategies to increase service access and equity. The third article (Morrow et al. 2020) illustrates the use and potential efficiency of machine learning methods to identify, among youth experiencing a specific problem, Attention Deficit Hyperactivity Disorder (ADHD), and their families, factors that distinguish those who have accessed services from those who have not. The national survey data to which the machine learning models were applied in this article do not qualify as "big data"- - the realm in which and for which machine learning techniques and the algorithms they generate have proliferated. That realm is characterized by huge volumes of digital data (for example, user data that feed algorithms used by web-based search engines, social 
media applications, and streaming services); genomic data, and increasingly, other types of medical data, the volume, structures, and proliferation of which defy more traditional approaches to statistical modeling (Beam and Kohane 2018; Insel 2012). Instead, this article illustrates the promise of applying machine learning approaches to "smaller" datasets to illuminate its potential for improving knowledge about children's mental health service use.

\section{Theme Two: Implementation and Dissemination}

Although not typically considered to be an implementation and dissemination researcher, Len provided some early insights into several implementation and dissemination questions worthy of exploration and further investigation. Much of this interest resulted from his early program evaluation research and System of Care work. Several of his scholarly works have focused on trying to understanding what is inside the black box of services and identifying real-world factors that are critical to installing effective services in systems; these are often some of the foundational questions addressed in implementation and dissemination research. His work has helped call attention to issues of implementation and the need to empirically examine them. Moreover, the journal that he founded has provided a welcoming venue for original research on implementation and dissemination, and in turn helped to advance this as a field of research in its own right. As such, it was appropriate that several of the papers submitted to the special issue focused largely on issues of implementation and dissemination.

Specifically, Mersky et al. (2020) consider the implementation of a statewide initiative that aims to increase access to evidence-based treatments and strategies to navigate implementation barriers. The systematic review by Powell et al. (2020) aimed to identify barriers and facilitators of implementing evidence-based interventions for children and youth who have been exposed to trauma. Finally, the article by Pas et al. (2020) digs deep into aspects of coaching as a form of implementation support from the perspective of a cost analysis, to better understand some of the "hidden costs" associated with coaching as a form of implementation support.

\section{Theme Three: Preparing for Innovation: Design, Context, and Policy}

The papers in this section all point to the need to look toward the horizon line to bring science to bear on the design of effective systems and supportive structures that will undergird and sustain child and family healthy development over time. Looking ahead at ways to maximize the impact of interventions requires attention to broader issues that affect services and the outcomes to which they contribute. Specifically, the papers in this section address the interfaces of constituents for whom an intervention is designed (Lyon et al. 2020), and of organizations with information about innovations they seek to acquire (Fenwick et al. 2020). Organizational and workforce interventions are the focus of the systematic review conducted by Ouellette et al. (2020), whereas Dopp and Lantz (2020) identify broader upstream issues that are often the focus for policymaking. These issues extend beyond current service needs to determinants of population health, which for children include contextual and macro factors within communities that affect healthy developmental trajectories (Dopp and Lantz 2020).

\section{Learning from and with Len Bickman: An Interview}

Following this collection of original pieces, the Festschrift includes a unique interview-style paper which provides insight into factors and experiences that influenced and shaped Len's work. This intriguing piece on Len was written by committee member and co-author Susan Douglas, who was also a former student of Len's. This paper highlights the innovative and disruptive nature of his career to date. Len describes how his early training in psychology instilled in him an appreciation for theory and program evaluation, which he has over the course of his career applied and often stretched or questioned in his work on program theory and mental health services. He concludes with some recommendations for future generations of mental health services researchers, which include gems like "Be a skeptical optimist", an aphorism that fits Len perfectly.

\section{Len's Opus on the Future of Mental Health Services Research}

The special issue also features an original paper by Len, which focuses on the future of mental health. In his article entitled, Improving Mental Health Services: A 50 Year Journey from Randomized Experiments to Artificial Intelligence (Bickman 2020), Len highlights the potentially pivotal role that innovative technologies including artificial intelligence and telehealth could play in the delivery of mental health services. In this work, he also identifies opportunities to further capitalize on machine learning and other emerging methodological approaches to enhance the delivery of mental health services. This penultimate article by Len encapsulates the trials and triumphs of the last 50 years and offers a vision for more potent, rapid, and meaningful advancement.

The process whereby the final version of this paper was crafted is further illustrative of Len's lifelong dedication to learning from colleagues. The original submission of the manuscript underwent blinded peer review, although by virtue of the content, the reviewers were not blinded to the author's identity. Each of the three reviewers offered extremely thoughtful and detailed critiques to the original 
submission. Len learned a lot from the reviews and thought substantive expansion of the points made in them would be edifying for the field. In fact, Len was so intrigued and challenged by the comments that his response was to suggest to the guest editors that we invite these individuals, whose identities were unknown to him at the time, to provide commentaries on the article that would also appear in this special issue. Len also wanted to ensure the reviewers received acknowledgement for inspiring him to consider, investigate further, and incorporate in his resubmission several points offered in their reviews. We wholeheartedly agreed. We are grateful that these esteemed reviewers, C. Hendricks Brown, John R. Weisz, and Wolfgang Lutz, faced with a "no good deed goes unpunished" request, were willing to write these commentaries and to invite collaboration in so doing from colleagues working with them at the cutting edges. We believe the intriguing ideas outlined in the forward-facing piece by Len, along with the accompanying commentaries by Brown (2020), Horn and Weisz (2020), and Lutz et al. (2020) will inspire several ideas for future research and perhaps incite some controversy, which is true to Len's style.

\section{Personal Reflections Spanning 50 Years}

We also solicited a set of reflections on Len, both personally and professionally, from colleagues and friends. These brief notes and letters reflect the significant impact he has had on many careers and lines of research, through his scholarship but perhaps more importantly as a mentor, colleague, and friend. These comments illustrate the range and profound impacts of mentorship and collaborative relationships with Len, some of which have spanned his 50 year career.

\section{Conclusions: Building Back/Forward Better}

In reflecting on Len's body of work, only a fraction of which we had space to feature on this special issue, one word that is often associated with him is "disruption" (Douglas 2020). In fact, this term has become a buzzword for change that both exposes faults and provides a new alternative. For example, blood pressure cuffs in grocery stores solved the dual problem of lack of access to preventive services and need for ongoing monitoring, leading to clinics that provide primary care and prevention more broadly. But disruption can also have unintended negative consequences. The Apple iPod made music more accessible but musicians struggle to make a living without the sale of albums and CDs. Amazon rocked the world of commerce with online sales of books without the expense of brick and mortar buildings and now bookstores are fast becoming an endangered species.

Children's mental health services has had its own disruptions over the years and one of the more dramatic was the call to reorganize mental health services to promote parent empowerment and children's clinical and functional improvements in the 1980s. Termed "System of Care," the model upended the traditional service model by emphasizing the need for various providers from different service sectors, representing distinct disciplines in often disparate locations, to establish a network of services with a common focus to support families and improve children's mental health. There were few that argued that these changes were not warranted or that the old system of top-down decision making that too often neglected parental concerns and perspectives was not due for overhaul. The System of Care model was adopted by all 50 states and was fanned by the enthusiastic support and significant funding from the Substance Abuse and Mental Health Services Administration (SAMHSA).

But if predicting the future is tough, insisting on evidence may be even tougher.

As System of Care swept across the country, Len was prescient enough to see behind the curtain; not only the lack of evidence for improved outcomes, but also the lack of a way to monitor changes. In two seminal studies, first at an Army base in Ft. Bragg North Carolina, and then at the one site that all proponents selected as the best in the country in Stark County Ohio, Len unraveled the System of Care model in two ways. First, in both cases the programs successfully implemented key elements of System of Care so that it could not be said that the model was not implemented faithfully. Second, he showed that youth did not benefit in any substantial way. SAMHSA seemed hardly to notice, as funding continued for many years after, thereby encasing the model in service systems and settings with little regard for data or outcomes. But many of us took notice, and it is fair to say that his studies ignited a new generation of children's mental health services research.

Though inspired by the quality of these studies and their implications for new models of change, this new research needed a home and at the time there was not much to choose from. To be sure, there were psychology or psychiatry journals that published the accumulating evidence for the efficacy or effectiveness of short-term, direct, interventions focused on specific problems and disorders. That seemed one part of the solution neglected by the System of Care. Standard psychology journals, such as the Journal of Consulting and Clinical Psychology, were open to new evidence for targeted interventions. But these journals tended to focus on efficacy trials in university settings rather than the decidedly untidy world of community-based services. As the paradigm of effectiveness research and later dissemination and implementation science took hold in the 2000s, Len merged two journals to provide a place for a new generation of mental health services research. The Journal of Administration and Policy in Mental Health and Mental Health Services Research-admittedly an awkward name if there 
ever was one-focused on the decidedly untidy natural settings of community-based care in which a new generation of research was spawned that focused on promoting effective and accessible care. This journal, affectionately called "Len's journal" by many of us, has become a major outlet for the fresh, critical and emerging science on mental health services in the public sector.

As we now are in a time of major upheaval and economic, societal, and institutional disruption of the public and private sectors caused by the COVID-19 pandemic and the devastating impact of racism in the U.S. and elsewhere across the globe, the need for disciplined and rational thinking, prescience, and intellectual clarity is stronger than ever. Specifically, the COVID-19 pandemic and the increasing recognition of the persistence of racism illustrated by numerous incidents of police brutality toward Black people in the U.S. are just some of the recent events which have exposed stark disparities in health and mental health services that have long plagued the country. These externally-imposed societal disruptions require intellectual clarity, creativity, and agility. Moreover, piecemeal solutions and guild-driven models are yesterday's failures. The system is, and has been, in need of dramatic overhaul. We urgently need agile intellectual disruptors to show us what is, and is not, a new way forward.

The papers in this special issue illustrate some of the ways in which new pathways may be pursued. As the country gradually recovers from the COVID- 19 pandemic and in-roads are made to begin to address some of the significant pain and damage resulting from over three centuries of structural racism in the U.S., there is an opportunity to "build back better"-i.e., to adopt the United Nations framework for recovery after disasters and commit to rebalancing resources and creating responsive and scientifically-based systems of community-based care that support families and promote children's healthy development, and more equitable access to services for all children. This is just one of the many reasons why the publication of this Festschrift acknowledging Len's many contributions is especially timely.

\section{References}

Beam, L., \& Kohane, I. S. (2018). Big data and machine learning in health care. JAMA, 319(13), 1317-1318. https://doi.org/10.1001/ jama.2017.18391MA.

Bickman, L. (1999). Editorial: Introductory statement. Mental Health Services Research, 1(1), 1-3.

Bickman, L. (2020). Improving mental health services: A 50 year journey from randomized experiments to artificial intelligence. Administration and Policy in Mental Health and Mental Health Services Research. https://doi.org/10.1007/s10488-020-01065-8.

Brown, C. H. (2020). Three flavorings for a soup to cure what ails mental health services. Administration and Policy in Mental Health and Mental Health Services Research. https://doi.org/10.1007/ s10488-020-01060-z.

Dickson, K. S., Stadnick, N. A., Lin, T., \& Trask, E. V. (2020). Defining and predicting high cost utilization in children's outpatient mental health services. Administration and Policy in Mental Health and Mental Health Services Research. https://doi.org/10.1007/s1048 8-019-00988-1.

Dopp, A. R., \& Lantz, P. M. (2020). Moving upstream to improve children's mental health through community and policy change. Administration and Policy in Mental Health and Mental Health Services Research. https://doi.org/10.1007/s10488-019-01001-5.

Douglas, S. (2020). An innovator and a disruptor: Leonard Bickman on program theory, null findings, and advice to future child mental health services researchers. Administration and Policy in Mental Health and Mental Health Services Research. https://doi. org/10.1007/s10488-020-01043-0.

Duncan, L., Georgiades, K., Reid, G. J., Comeau, J., Birch, S., Wang, L., et al. (2020). Area-level variation in children's unmet need for community-based mental health services: Findings from the 2014 Ontario Child Health Study. Administration and Policy in Mental Health and Mental Health Services Research. https://doi. org/10.1007/s10488-020-01016-3.

Fenwick, K. M., Palinkas, L. A., Hurlburt, M. S., Lengnick-Hall, R. D., Horwitz, S. M., \& Hoagwood, K. E. (2020). Acquisition of information about innovative practices in outpatient mental health clinics. Administration and Policy in Mental Health and Mental Health Services Research. https://doi.org/10.1007/s10488-02001029-y.

Horn, R., \& Weisz, J. R. (2020). Can artificial intelligence improve psychotherapy research and practice? Administration and Policy in Mental Health and Mental Health Services Research. https:// doi.org/10.1007/s10488-020-01056-9.

Insel, T. (2012). An emerging era of big data. Blog post. https://www. nimh.nih.gov/about/directors/thomas-insel/blog/2012/an-emerg ing-era-of-big-data.shtml.

Lutz, W., Schwartz, B., Gomez, J. M., Boyle, K., \& Deisenhofer, A.-K. (2020). Working towards the development and implementation of precision mental healthcare: An example. Administration and Policy in Mental Health and Mental Health Services Research. https://doi.org/10.1007/s10488-020-01053-y.

Lyon, A. A., Dopp, A. R., Brewer, S. K., Kientz, J. A., \& Munson, S. A. (2020). Designing the future of children's mental health services. Administration and Policy in Mental Health and Mental Health Services Research. https://doi.org/10.1007/s10488-020-01038-x.

Mersky, J. P., Topitzes, J., Janczewski, C. E., Plummer Lee, C.-T., McGaughey, G., \& McNeil, C. B. (2020). Translating and implementing evidence-based mental health services in child welfare. Administration and Policy in Mental Health and Mental Health Services Research. https://doi.org/10.1007/s10488-020-01011-8.

Morrow, A. S., Campos Vega, A. D., Zhao, X., \& Liriano, M. M. (2020). Leveraging machine learning to identify predictors of receiving psychosocial treatment for Attention Deficit/Hyperactivity Disorder. Administration and Policy in Mental Health and Mental Health Services Research. https://doi.org/10.1007/s1048 8-020-01045-y.

Ouellette, R. R., Goodman, A. C., Martinez-Pedraza, F., Moses, J. O., Cromer, C., Zhao, X., et al. (2020). A systematic review of organizational and workforce interventions to improve the culture and climate of youth-service settings. Administration and Policy in Mental Health and Mental Health Services Research. https:// doi.org/10.1007/s10488-020-01037-y.

Pas, E. T., Lindstrom Johnson, S., Alfonso, Y. N., \& Bradshaw, C. P. (2020). Tracking time and resources associated with systems change and the adoption of evidence-based programs: The "hidden costs" of school-based coaching. Administration and Policy 
in Mental Health and Mental Health Services Research. https:// doi.org/10.1007/s10488-020-01039-w.

Powell, B. J., Patel, S. V., Haley, A. D., Haines, E. R., Knocke, K. E., Chadler, S., et al. (2020). Determinants of implementing evidence-based trauma-focused interventions for children and youth: A systematic review. Administration and Policy in Mental Health and Mental Health Services Research. https://doi.org/10.1007/ s10488-019-01003-3.
Publisher's Note Springer Nature remains neutral with regard to jurisdictional claims in published maps and institutional affiliations. 